\title{
Laparoscopic Left Lateral Sectionectomy Using the Extrahepatic Glissonean Approach: A Secure Option for Achieving a Negative Margin for Lesions with Ductal Extension
}

\author{
Satoshi Ogiso, MD, PhD, FACS ${ }^{1}$, Satoru Seo, MD, PhD ${ }^{1}$, Shinya Okumura, MD, PhD, FACS ${ }^{1}$, \\ Takamichi Ishii, MD, PhD ${ }^{1}$, Ken Fukumitsu, MD, PhD ${ }^{1}$, Takashi Ito, MD, PhD $^{1}$, Toshihiko Masui, MD, PhD $^{1}$, \\ Kojiro Taura, MD, PhD ${ }^{1}$, Toshimi Kaido, $\mathrm{MD}, \mathrm{PhD}^{1}$, and Shinji Uemoto, MD, $\mathbf{P h D}^{1}$ \\ Division of Hepato-Biliary-Pancreatic Surgery and Transplantation, Department of Surgery, Graduate School of Medicine, \\ Kyoto University, Kyoto, Japan
}

\begin{abstract}
Introduction. In patients with liver lesions with ductal extension, the corresponding Glissonean pedicle should be divided at its origin to achieve a negative ductal margin; however, during laparoscopic hepatectomy, it is difficult to precisely transect the liver and divide the Glissonean pedicle as planned.

Methods. We present a video of a laparoscopic left lateral sectionectomy using the extrahepatic Glissonean approach for a lesion with ductal extension.

Results. A 76-year-old woman presented with a cystic neoplasm in the liver segment 3 bile duct (B3). The preoperative workup suggested biliary extension of the lesion towards the origin of B3. A decision was made to perform laparoscopic left lateral sectionectomy with division of the segment 3 Glissonean pedicle (G3) at its origin, and, additionally, left hepatectomy if the B3 ductal margin turned out to be positive. During the procedure, prior to parenchymal transection, the Arantius' ligament was dissected, and G2 and G3 were extrahepatically taped. The
\end{abstract}

ischemic border was visualized by clamping the isolated pedicle, and was also clearly demonstrated by indocyanine green fluorescence. After transecting the liver towards the tape, G3 was divided at its origin, and the frozen section of the ductal margin was negative for tumors.

Conclusion. The extrahepatic Glissonean approach can help to obtain a maximal ductal margin for liver lesions with possible biliary extension, although the technique potentially poses the risk of bleeding and/or biliary injury, and requires expertise in hepatobiliary surgery. Further studies with larger sample sizes are warranted to validate the feasibility and efficacy of this strategy.

DISCLOSURES The authors have no conflicts of interest to declare.

Publisher's Note Springer Nature remains neutral with regard to jurisdictional claims in published maps and institutional affiliations.
Electronic supplementary material The online version of this article (https://doi.org/10.1245/s10434-019-07298-8) contains supplementary material, which is available to authorized users.
(C) Society of Surgical Oncology 2019

First Received: 22 December 2018;

Published Online: 18 March 2019

S. Seo, MD, PhD

e-mail: rutosa@kuhp.kyoto-u.ac.jp 